By VERNON D. TATE

\title{
Defrosting a Frozen Asset: The Publication of Doctoral Dissertations
}

Dr. Tate is director of libraries, Massachusetts Institute of Technology.

$A^{r}$ FTER the baccalaureate, advanced academic degrees except honorary awards are achieved by a combination of formal study, examinations and the completion of a significant piece of advanced research, in the terms of the university catalog "an investigation together with the written report and interpretation thereof on a subject approved by a departmental committee on graduate students in advance of the beginning of research." Physically the report is usually a typed manuscript prepared with a good deal of pain in accordance with precise regulations on format that is deposited in the university library. At certain universities candidates are still required to publish their dissertations or guarantee publication. In most cases only a typewritten original and the number of carbon copies that the candidate can persuade or afford to subsidize his typist to make are prepared and one or more copies are deposited in the library. These doctoral dissertations original manuscripts for the most part are usually available in one place and at best can be consulted elsewhere only through the slow and restricted provisions of the interlibrary loan system. They form a gigantic frozen asset of American scholarly research.

It has become fashionable to pooh pooh the value of the dissertation and to term it a mere intellectual exercise of little real significance or practical value, and it would be foolish to deny that some dissertations are rarely if ever read again even by the authors. Conversely others are extremely important. Scoffers might ponder the fact that in the period I949-5I, 6324 doctoral dissertations were requested on loan from 44 research libraries. Of these 5I55 were available and i 69 were not. Despite existing difficulties in locating titles and gaining access to the dissertations themselves, there is a real and growing demand for the products of doctoral research.

In 1913, Charles A. Flagg prepared $A$ List of American Doctoral Dissertations Printed in 1912 which was issued by the Library of Congress. It was, incidentally, a volume of 106 pages listing 26 I titles supplied with an alphabetical and a classified list arranged under the broad classes of the Library of Congress scheme, a subject index and a list of authors by institutions; it was available from the Government Printing Office at a price of 30 cents. This list appeared annually until I938, but an important qualification of its research value was the premise on which it was compiled: "The list contains only the dissertations received by the Library of Congress, and is not, therefore, to be considered in every instance a complete list of dissertations issued at a given university." Meanwhile the Association of Research Libraries undertook to compile Doctoral Dissertations Accepted by American Universities, of which, Number 
I, I933-34, edited by Donald B. Gilchrist, was published in 1934 under the joint auspices of the National Research Council and the American Council of Learned Societies. In the preface it was pointed out that the recording of American Doctoral Dissertations has been "fragmentary and haphazard," and that the present list which carried on in much the same form as earlier lists published by the National Research Council includes all fields of study. The most recent volume of this series, Number I 8, I950-5 I compiled for the Association of Research Libraries and edited by Arnold H. Trotier and Marian Harman listing 7477 dissertations in 266 pages is available at a price of $\$ 4.50$. In the period I9I3-I95 I the number of titles recorded has multiplied more than 28 times. In the same interval printing requirements and availability have frequently changed. Of I05 degree granting institutions listed in the current volume with some qualifications in each instance, 36 require printing, 43 publish abstracts; all but three supply manuscript copies to the library, and of the three not placing manuscript copy in the library two require printing. Most of the institutions, although not all, regularly loan either a typed manuscript or a printed copy of a dissertation, or can arrange to supply microfilin reproductions.

In 1938 a private publication venture addressed to the publication of dissertations made a modest 32 page debut with the publication of Volume I, Number I of Microfilm Abstracts by University Microfilms of Ann Arbor, Michigan. Subtitled "A Collection of Abstracts of Doctoral Dissertations and Monc graphs Available in Complete Form on Microfilm," the volume resulted from an interest in the use of microfilm as a publication medium. The essentials of the plan included the submission by the author of the original typed manuscript dissertation together with a 600 word abstract. After being reproduced on $35 \mathrm{~mm}$. microfilm, the manuscript is returned, and the master negative placed in storage. The abstract is printed in Microfilm Abstracts, which was circulated without charge to leading libraries in the United States and abroad, and to certain journals and abstracting services. Catalog entries are forwarded to the Library of Congress where printed cards are made and distributed. The fee for these services, payable either by the author in lieu of conventional publication or by the degree granting institution, at the outset was $\$$ I 5 .0o but at the date of writing is $\$ 20.00$, irrespective of the length of the original manuscript. If the research worker after consulting the abstract wishes to read the complete paper he may secure direct from University Microfilms either a positive microfilm made from the original negative at a per page cost of $\$ .0125$ (one and one quarter cents) or enlarged paper photoprints at \$.Io (ten cents) each. Publications in this form are eligible for copyright protection. The plan has been described as approaching the ideal enunciated by Binkley as publication to order in editions of one. An increasing number of universities and other degree granting institutions have favored the plan, and the current Volume XI, I95 I of Microfilm Abstracts totals I2 I 2 pages, that however include a relatively small number of monographs which are not dissertations.

For the past two years a committee of the Association of Research Libraries has been engaged in studying the problem of dissertation availability. The committee includes Ralph E. Ellsworth, director of libraries, Iowa State University (chairman), Ralph Sawyer, dean of graduate studies, University of Michigan, Henry Silver, staff consultant on publications, American Council of Learned Societies, and Vernon D. Tate, director of libraries, Massachusetts Institute of Technology. After surveying the field 
with some care the committee concluded that beyond question dissertations are valuable and useful research materials and that the existing methods of dissemination are completely inadequate. Three principles were formulated as a basis for attempting a solution of the problem:

(a) That all doctoral dissertations accepted by institutions of higher learning in the United States should be published in order that the information they contain can be more effectively communicated than is possible through a costly and inefficient and in any case incomplete system of interlibrary lending of manuscripts or printed copies.

(b) That the form of publication is of no special importance to the committee.

(c) That abstracts and other information necessary for locating published dissertations should be made regularly available in one central bibliographical source.

Conventional publication in the form of articles, monographs and books, if financially practicable and if combined with suitable bibliographical apparatus, would supply an answer. This traditional approach has completely failed thus far and with rising costs of printing it is apparent that scholarship cannot absorb the expense of publishing approximately 6000 odd dissertations completed each year. Auxiliary techniques of publication, microfilm, microcards and microprint were investigated, with particular attention to the plan developed by University Microfilms. It appeared that with certain alterations the University Microfilms plan offered real advantages. The obvious point that centralization of dissertation publication in the hands of a single commercial enterprise might not be desirable was thoroughly explored. It was pointed out, however, that traditionally and practically commercial publication is the universally accepted channel for disseminating scholarly material and if completely available without subsidy for dissertations would solve the problem. Moreover, adequate safeguards can be developed to protect all participants.

Accordingly, a plan was perfected which provides bibliographical control through the continued publication of Doctoral Dissertations Accepted by American Universities and the issuance of a new bi-monthly abstracting publication combined with effective arrangements whereby any dissertation listed can be made available in the form of $35 \mathrm{~mm}$. microfilm or enlarged paper prints in editions of a single copy to order at moderate prices. The plan, accepted and approved by the Association of Research Libraries at its winter meeting, includes the following provisions :

I. University Microfilms of Ann Arbor, Michigan will become the central agency for the publication of abstracts of doctoral dissertations, and with certain reservations the source of complete texts of dissertations.

2. Microfilm Abstracts formerly published as a quarterly will be discontinued. A new publication Dissertation Abstracts will be created to publish abstracts of dissertations and title listings. It will appear six times per year with the sixth number comprising the index for the year by title and author. It is projected that the annual indexes will be supplemented by five year cumulations. Dissertation Abstracts will be available on a subscription basis at $\$ 6.00$ per year.

3. Interlibrary loan of dissertations will be discontinued.

4. Participation in the plan by degree granting institutions is voluntary and may be achieved on any one of the following bases:

A. Full participation-fee $\$ 20.00$ per title; will include the preparation of a master microfilm negative from the original dissertation shipped to University Microfilm, Ann Arbor; storage of the negative and the production of positives to order at the 
standard rate (approximately \$.or 1 cents per page) and the printing in Dissertation Abstracts of an abstract of up to 600 words. It will not include the cost of a positive microfilm to the depositing university library or a free copy of Dissertation Abstracts.

B. Limited participation-fee \$12.00; institution will make the master microfilm negative to established specifications and will send it to University Microfilms for servicing; includes the printed abstract but does not include a positive copy or a copy of Dissertation Abstracts.

C. Limited participation-fee \$15.00; institution makes and services the negative or other facsimile. Includes printing of 600 word abstract as above but not a copy of Dissertation Abstracts.

I.) The full text may be made available as:

a. book b. journal article c. microfilm d. microcard e. microprint $f$. other type of reproduction

D. Limited participation-fee $\$ 2.00$; title listing only. (For institutions publishing their own abstracts of dissertations and prepared to supply copies of the full text.); includes printing of title in annual index (two places, title and author index) and in the five-year cumulation.

The plan as it was finally developed represents considerable study on the part of the committee. It completely meets the three basic principles, namely, that all doctoral dissertations accepted by institutions of higher learning should be published; that the form of publication is of no special importance; that abstracts and other information necessary for finding published dissertations should be made periodically available in one central bibliographical source.

It is important to note that participation in the plan can be achieved on any level to meet the needs of any institution. If, for example, a university possesses the requisite facilities to make the master microfilm negative, it may do so and then either retain the negative for servicing in its own laboratory or send it to University Microfilms for servicing, in. either case supplying an abstract for publication in Dissertation $A b$ stracts in order to complete the bibliographic record. The same situation will prevail should the dissertation be printed as a book or monograph, made available on microcards or published as a research report, for publication obviously does not depend on the availability of a microfilm copy. If in addition the institution publishes its own volume of abstracts then title listing only will ensure the bibliographical record. Possibly central publication of abstracts of dissertations might reduce the cost below the level of an individual volume and result in a saving in printing costs although this point remains to be determined.

For the candidate, the plan will insure prompt publication of his dissertation, afford it a place in the literature of his field without undue financial burden; at the same time it will afford him copyright protection if desired without in any way prejudicing plans for future publication of his dissertation as a book or monograph. Scholars and users of dissertations will be able to survey a particular field far more readily than in the past and having located material be insured of prompt access to it. It is true that scholars will have to learn to use a new bibliographic tool, and that reading from $\mathrm{mi}$ crofilm is considered by some to be less convenient than reading from the original text, although those who have encountered poor carbon copies might be inclined to debate the point. It might be that with the publication of all dissertations the quality of research and reporting which has been questioned in some quarters will improve. For the librarian as for the research worker

(Continued on page 45) 
lished is correct, whether the serial shall be analyzed, and whether it shall be classified. If it is to be classified, the call number is entered on the work slip. The work slip, with notes referring to the decisions mentioned above, is then returned to the Central Serial Record where the information is transcribed to the checking card. Flexoline strips are then typed for each of the two Flexoline files and are forwarded to the Reference librarian and the Periodical Service librarian. They may, or may not, interfile the new title in their Flexoline files, depending upon their estimate as to how much demand will be made for that particular title. It should be remembered that these files are selective and are designed primarily as a location guide and an easy method for locating call numbers.

\section{Summary}

Centralizing serial records is nothing new to serials librarianship, but the concept of a Central Serial Record seems to be a product of the past decade. It is a development which has been largely forced on larger libraries by the growing complexity and increased administrative costs connected with maintaining records for their serial holdings. It has been made possible by critically examining the actual use made of records which have been kept for the sake of the custom. Duplicate records, and records whose use did not warrant their maintenance, have been eliminated. Records which were found to be necessary to the efficient management of the Serials Division have been consolidated into filing equipment that performs far greater service than the conventional catalog tray. Mechanical methods of communication have come to play an increasingly important part, as it has been realized that the installation of a telephone or the extension of a pneumatic tube system would be quickly paid for by the savings resulting from record consolidation. Despite some slight delay for the marginal patron who has to know the holdings of a particular title, it is felt that patron service on the research level has taken a great step forward by the provision of a comprehensive serial record.

\section{Defrosting a Frozen Asset}

\section{(Continued from page 38)}

access to dissertation materials will become immensely easier than before and the heavy burden of interlibrary loan will be correspondingly eased by the elimination of dissertations from the loan code. The machinery of interlibrary loan is already creaky and showing signs of distress and any relief will be most welcome. It may mean moreover that the costly binding of dissertations may in the future be eliminated.

To the extent that degree granting in- stitutions cooperate and participate in the plan, it will succeed. It should be a prime obligation of every librarian interested in the future of advanced scholarship to bring the plan before the Graduate School at as early a date as possible and to support it vigorously. Organized regular listing of dissertations coupled with availability of abstracts and facilities for gaining prompt access to the complete texts will defrost this frozen asset of American scholarship. 